Practice placement education is an essential component of health professional programmes. The number of students with a disability entering health professional education programmes is anticipated to rise, yet research about the perspectives of students with a disability is limited, especially related to practice placement education. Therefore, the need to investigate student experiences has intensified.

In this study, qualitative research methodology was used to investigate the perceptions, feelings and experiences of health professional students with a disability during practice placement education. Five health professional students, recruited from a regional university in New South Wales, Australia, participated in semi-structured, individual interviews. A phenomenological approach was used.

Following inductive analysis of the data, three themes reflecting the students' experience of practice placement education emerged: the impact of disability, including the barriers and the strategies used to overcome these; the experiences of practice placement education, including the feelings of the participants; and support, which came from the practice placement educator, the university staff, family and friends.

This pilot study provides valuable insight into the perspectives of these students about practice placement education. The findings reinforce the need for further exploration of the unique experiences of students with a disability to ensure success within their university programme and future profession.

\title{
The Practice Placement Education Experience: an Australian Pilot Study Exploring the Perspectives of Health Professional Students with a Disability
}

\author{
Kate Brown, Carole James and Lynette Mackenzie
}

\section{Introduction}

To ensure the optimal development of the occupational therapy profession, the educational experiences of students with a disability and the services offered by students to clients, there is a need for health professional clinicians, practice placement educators and academics to work together in providing fair and ethical practice placement education (Hirneth and Mackenzie 2004). A previous study conducted in Australia with practice placement educators indicated that the process of practice placement education for occupational therapy students with a disability was a complex one for both professionals and students. Issues were identified relating to the need for practice placement educators to understand how to balance their responsibilities to accommodate students with a disability; to facilitate learning opportunities, in sometimes difficult environments; and to provide a fair assessment of student progress (Hirneth and Mackenzie 2004). This paper focuses on the student perspective of experiencing practice placement education with a disability in the health field.

\section{Literature review}

\section{Background}

Legislation demands non-discriminatory processes within practice placement education in both the United Kingdom and Australia. In Australia, educational institutions are required by law to eliminate discrimination against students on the grounds of disability and are required to make reasonable accommodation and modification to allow individuals with a disability to use their services to the same extent as others (New South Wales Ageing and Disability Department 1998). Furthermore, the number of students with a disability enrolled in higher education in Australia is increasing (Commonwealth Department of Education, Science and Training [DEST] 2003).

The Special Educational Needs and Disability Act 2001 is British legislation that requires educational institutions to accommodate students with a disability, including those that incorporate a practice placement education component (Skill: National Bureau for Students with Disabilities 2005). Specifically, educational institutions 
may have to accommodate students with a disability by making changes to the policies and practices (for example, admission procedures), course requirements, practice placements, physical features of a building, provision of interpreters or other support workers, delivery of courses in alternative ways and provision of material in other formats. Many of these examples may also apply to the practice placement education environment. The Act allows for justifiable discrimination in relation to academic standards and other prescribed standards and the need for disclosure by the student with a disability if accommodations are to be made.

\section{Experiences of students with a disability}

Rangel et al (2001) identified an increase in the number of students with a disability choosing to pursue careers as health care professionals, such as in medicine, nursing, physiotherapy and occupational therapy programmes. In any programme, university students with a disability are faced with the challenges of university life; however, in health professional programmes, these students are also required to undertake practice placement education in addition to academic course requirements. Anecdotal evidence suggests that prospective health professional students may need to be articulate and confident negotiators and to be knowledgeable about university procedures and networks as they pursue admission and progress through a course of study (Skill: National Bureau for Students with Disabilities 2005).

Practice placement education is an integral part of all health professional programmes and provides the opportunity for students to develop competence and learn in a practical environment. These experiences complement and support theoretical knowledge and allow students to integrate this theory with practice (Tompson and Ryan 1996). Mitchell and Kampfe (1990) identified that this transition from the academic setting to practice placement education was considered by numerous occupational therapy students as a source of stress. Students with a disability in health professional programmes may need to overcome additional stressors and barriers related to their disability to make the practice placement education experience positive. Barriers to successful higher education for students with a disability have been identified largely as physical (accessibility and adaptability), social (negative attitudes, stereotyping and stigmatisation, and lack of support), institutional (lack of policies and procedures) and interpersonal (non-disclosure and limitations caused by disability) (Baron et al 1996, Gitlow 2001).

The health professional student, undertaking practice placement education, is also faced with the pressures of professional practice in a clinical environment. Support and assistance are essential to enable engagement in practice placement education, to assume their occupational role as a university student and to enhance opportunities for success within their chosen health profession (Llorens et al 1999). The barriers that students with a disability may encounter during the academic programme and practice placement education, and the need for university and clinical staff to provide support and accommodation to eliminate these, have been recognised by numerous authors, including Kornblau (1994), Marks (2000) and Wright (2000); however, there has been little inclusion of the students' perspective in the research process. It is essential that the needs, identified by the students themselves, are incorporated into programme policies, services provided and identification of reasonable accommodations.

The lived experience of university life from the perspective of students with a disability (Anderson et al 1996, Weiner 1999, Holloway 2001) and professional health care workers' experiences of professional practice with a disability (Pohl and Winland-Brown 1992, Velde 2000) have been previously investigated, with studies coming from the United Kingdom, Canada and the United States. However, although there has been research related to the perspectives of students about practice placement education (Christie et al 1985, Hummell 1997), there has been little published about the experiences of disability from the perspective of health professional students and, specifically, the issues encountered during their practice placement education experiences, as emphasised by Coffey (2001).

Archer (1999) detailed his own personal journey and the challenges encountered during practice placement education and university as an occupational therapy student with a learning disability. He achieved success after full disclosure, with appropriate support from academic and clinical staff, with the implementation of reasonable accommodations and by developing personal coping strategies. Maheady (1999) found that American nursing students with a disability were confronted with challenges, including fear of disclosure and attitudinal and physical barriers. Baron et al (1996) identified five barriers to academic and practice placement education that Scottish social work students with a disability encountered: the environment, stereotypes, failure of equal opportunity policies, staff assumptions of normality and self-limitation (reluctance to disclose and identify needs). These studies touch on the issues arising from practice placement education for health professional students with a disability, although the need to take an in-depth look at practice placement education and the disabled student experience continues to exist.

This study explored the perceptions, feelings and experiences of practice placement education of a small group of health professional students with a disability who were studying at the University of Newcastle in New South Wales, Australia. The university uses a computer programme for enrolments to record voluntarily disclosed information about student disabilities, impairments or long-term medical conditions that may affect their studies. This was used to identify potential participants for this study. An adaptation of the Anderson et al (2002) definition of health professional was used to define a health professional student as 'any person who is completing a course of study in a field of health, such as nursing, 
physiotherapy or medicine'. A qualitative pilot study was designed with the aim of answering the research question: how do health professional students with a disability experience practice placement education? The primary purpose of this research was to explore and describe both the positive experiences and the difficulties encountered by these students during practice placement education and the factors that made their experiences more successful.

\section{Method}

A qualitative, phenomenological approach was adopted, because this approach seeks to describe, understand and interpret experiences from the perspective of those experiencing the phenomenon (Depoy and Gitlin 1994). Semi-structured, face-to-face interviews generated large amounts of descriptive data of each participant's experiences.

\section{Participants}

The participant inclusion criteria required all students:

1. To be enrolled in a health professional programme at the University of Newcastle that included practice placement education; these included nursing, occupational therapy, physiotherapy, social work, speech therapy, medicine, medical radiation science, and nutrition and dietetics programmes

2. To self-identify as a student with a disability that met the definition outlined for this study

3. To have completed at least one practice placement education experience as part of their university course requirements.

All individuals who met the research criteria and volunteered to participate were included in the study.

\section{Procedure}

Following ethical approval from the University of Newcastle Research Ethics Committee, the participant group was identified from students who were registered at the University Student Support Service (Disability) and students who had indicated on their enrolment form that they had some form of disability, impairment or long-term medical condition. The potential participants were sent information letters through the student email system by the university Disability Liaison Officer. Since the database was unable to identify those students who had undertaken practice placement education, an estimation of the number of eligible participants was not possible. However, 91 emails were sent and 10 students responded to the researcher with interest, with five consenting to participate in the study. The consenting students were then contacted to organise a convenient time and place for the interview.

\section{Data collection}

The data were collected by in-depth, one-to-one interviews using a semi-structured interview schedule. This schedule provided a framework of topic areas to be addressed in the interviews and ensured that similar issues were explored with each participant (Patton 2002). The use of open-ended questions encouraged descriptive responses to develop according to each participant's own narrative style and facilitated opportunities for the researcher to probe further into participant experiences (Suto 2000). All interviews were conducted in a private location on the university campus and ranged in length from 60 to 90 minutes. No participant required the use of communication aids or an interpreter. Each interview was audiotaped to increase accuracy of data and was transcribed verbatim. Researcher observations and reflections were also recorded in field notes to aid data analysis (Patton 2002).

\section{Data analysis}

The data analysis was an iterative process, whereby data were continuously subjected to analysis and reflected on during the data collection phase to guide the research process (Grbich 1999). The process of data analysis was inductive and dynamic in nature. Following completion of the data collection, the transcripts and field notes were read several times to gain an overview of the data as a whole. Recurring words and patterns within participants' experiences were sorted into categories and a coding system was developed and used to code all transcripts. Core categories were compared and contrasted and were sorted, allowing themes and subthemes to emerge from the data (Patton 2002).

\section{Trustworthiness}

Triangulation, member checking, reflexive analysis and peer review were incorporated into the study design to establish rigour. The triangulation of data methods (individual interviews, field notes and member checking) was used to strengthen the accuracy of the data and to ensure that all aspects of the phenomenon had been explored (Hammell and Carpenter 2000). Member checking involved contacting participants to confirm their responses, verify the identified themes and decrease the chance of misrepresentation of data. In addition, a reflexive field journal was kept for the duration of the research, allowing the researcher to examine the influence of personal biases and preconceptions on the data. Finally, consensus coding was used by the researchers to validate the codes identified in one transcript (Krefting 1991). These techniques are described by Krefting (1991) to enhance the credibility of qualitative research and to increase the likelihood of the representation of 'truth' in the description and interpretation of participants' subjective experiences of practice placement education.

\section{Findings and discussion}

Five students were interviewed: one male and four female, two of whom were nursing students and three occupational therapy students, with diagnoses of neural hearing loss, bipolar disorder (2), dyslexia and cystic fibrosis and having completed between one and eight practice placement 
education experiences. Three key themes emerged from the analysis, reflecting each participant's unique experience of practice placement education with a disability. These themes were the impact of disability on practice placement education, practice placement education experiences and support for practice placement education.

\section{The impact of disability on practice placement education}

Bruce (2001) highlighted that it could not be assumed that people with similar disabilities or impairments would have the same experiences, thus practice placement education experiences could be expected to be unique. The study participants had varied disabilities. Each participant described the individual barriers faced during practice placement education that related directly to their disability and their own perceptions of the individual nature of disability.

\section{Motivation}

Paul (1999) suggested that some individuals with a disability felt that society underestimated them and that this encouraged them to be highly motivated to achieve their goals. This determination to succeed in practice placement education, to prove not only to themselves but also to others, was expressed by participant 3 :

I like to prove people wrong ... especially with my last supervisor, as soon as I had that [negative] feedback I was really determined to go far beyond what I expected for myself ...

The participants identified the similarity of their experiences to those of non-disabled peers and their desire to be treated as such, consistent with the findings of Anderson et al (1996) and Maheady (1999):

I don't lower my expectations because I've got a disease, I still expect myself to do just as well as anyone (Participant 5).

In terms of my so-called disability, just not letting it really be a big issue - I still want to be treated like every other student (Participant 3).

\section{Disclosure}

The participants perceived a limited understanding of disability by others, including practice placement educators, university staff and peers, such as the description given by participant 3 :

It's really hard to have a good understanding of a disability unless it is yours I think, so supervisors, no matter how good they are, often don't really understand.

This limited understanding was identified by the majority of the participants to be closely related to non-disclosure of their disability during practice placement education. Other reasons for non-disclosure of a disability included perceptions by the participants that people had different attitudes towards them and that they did not want 'special treatment'. Participant 5 commented:
People have a different opinion of you when they find out ... and they treat you differently, whereas if you hadn't ever told them they might treat you normally.

As found in the present study, Marks (2000) suggested that students would be unlikely to disclose their disability if they perceived the possibility of a loss of status. Elliot et al (1992) found that occupational therapists expressed negative attitudes towards peers with psychiatric disorders, thus supporting the concerns of the participants regarding disclosure:

\section{Looking back I was hallucinating and had delusions ... what I saw was happening wasn't actually happening, so that was why I was reacting as I was and why I had to tell her (Participant 2).}

The participants indicated that disclosure would only occur when or if the need arose; for those who did disclose to their practice placement educator, it resulted from an issue related to the limitations and challenges of their disability:

The first time I told, we were walking towards the respiratory ward and I said 'I can't go in there' ...

I didn't really have an opportunity to explain anything ... (Participant 5).

Students with a disability that cannot be seen may not disclose until problems arise in their practice placement education experiences (Kornblau 1994, Archer 1999). In comparison, the participant with a 'visible' disability always disclosed at the beginning of practice placement education. Each participant described a mixture of feelings regarding disclosure, including nervousness, discomfort, worry, distress and fear. Participant 3 was the only participant who experienced negative reactions from several practice placement educators following disclosure:

I think they should react better because they are OTs and they are meant to have an understanding of disability.

\section{Overcoming barriers}

As highlighted within a number of studies (Anderson et al 1996, Archer 1999, Velde 2000), each participant implemented personal strategies to overcome barriers and ensure positive practical experiences. The strategies outlined by four participants included preparation, setting personal goals and expectations, planning how to adapt effectively to limitations, learning from previous experiences, developing personal coping mechanisms and having a positive outlook. Participant 2 explained that she would self-medicate, self-talk, do her duties on autopilot, make excuses to go home and focus on the end of each practical experience to 'cope' during her experiences. Consistent with Velde's (2000) research, the participants did not perceive the barriers that they experienced as having an impact upon their ability to perform as competent health professional students and future practitioners. 


\section{Practice placement education experiences}

\section{Feelings}

Nervousness, apprehension, uncertainty, worry and anxiety were all feelings described by participants regarding practice placement education. Participant 1 reported initial nerves:

... just the normal stuff [feelings] that everybody gets pretty much.

This finding is supported by Tompson and Ryan (1996), who revealed that occupational therapy students entering practice placement education experienced feelings of uncertainty in these unfamiliar environments with unknown expectations. Participant 2 explained that practice placement education:

was just like any other thing ... there are lots of things that I am always nervous and scared about, and placement has just got a few of them in it ...

Two participants also cited feeling excited when beginning each practice placement education experience.

Mitchell and Kampfe (1990) also found occupational therapy students' perceptions of practice placement education to be generally positive. Four participants in the present study indicated that they enjoyed the practice placement education and conveyed an increased confidence following completion of each one.

Participant 3 summarised her feelings, both positive and negative, stating:

... every practice [placement] education experience is valid, I think it'd be hard for anyone to say no matter how bad it was that they didn't get something out of it.

\section{Surviving practice placement education}

Participant 2 described her experience in terms of survival: at the completion of each practice placement education experience she would 'dread' having to complete another one. This is similar to the findings of Weiner (1999), where students with a psychiatric disability reported experiencing internal barriers to learning. These were related to the internalisation of feelings such as stigma, which affected a student's ability to disclose and ask for assistance. Participant 2 described:

... it was just the internalising of it all, worrying that it would happen, worrying that they would know, and worrying that they'd fail you because they might know and you weren't up to par. So probably more my impostor syndrome ...

Participant 5 commented, 'You always feel like you are in the way.' She did not like to inconvenience the practice placement educator any more than she needed to, a finding consistent with that of Baron et al (1996) where students expressed reluctance to contact the university regarding their needs because they felt this might cause them to be labelled a nuisance.

\section{Identifying with clients}

Maheady (1999) and Velde (2000) indicated that individuals with a disability working in the caring professions felt that they had an increased sensitivity to their clients' needs because they shared the disability experience. Participant 4 also held this view, explaining a unique rapport that she gained with clients during her practice placement education because she understood how they felt mentally.

\section{Support for practice placement education}

The importance of support from various groups both prior to and during the practice placement education experience was emphasised by all the participants. The role of practice placement educators was identified as being of pivotal importance in students having a positive experience:

... the main thing is that the supervisor needs to be understanding ... because they're what makes your experience really good or really bad (Participant 3).

Christie et al (1985) also emphasised the critical role of practice placement educators in facilitating a positive student practice placement education experience. Well developed interpersonal skills are essential characteristics for effective practice placement educators (Christie et al 1985, Hummell 1997) as suggested by participants, along with personal traits and skills, including approachability, understanding, communication and interest in supervision. The willingness of practice placement educators to accommodate the needs of students, the provision of feedback and the identification of practice placement education goals and expectations were also indicated as important. An understanding and knowledge of disability, as well as the importance of social support in overcoming barriers to higher education, have been identified as more important to students with disabilities than non-disabled students (Anderson et al 1996).

Satisfaction with the support received from the majority of practice placement educators was expressed by all the participants:

She was really good, and to have her say when I told her that it didn't really matter, it just meant that I had heaps more respect and I felt really confident ... (Participant 3 ).

\section{Importance of support}

Support was important in building confidence, reducing stress and alleviating pressure. Pohl and Winland-Brown (1992) and Maheady (1999) emphasised the importance of support in developing effective coping abilities. They found that inappropriate attitudes towards individuals with disabilities had an impact upon their self-esteem and confidence and increased their stress levels. Participant 3 stated:

... my practice [placement] educator seemed to kind of want to turn me into a client ... they should have been teaching me OT things not trying to teach me what was wrong with me which was not their role and not why I was there. 
The importance of support received from other staff members at the clinical site during these experiences in assisting to alleviate pressure was also discussed.

\section{Support from the university}

Support from the university was found to be adequate by most participants:

Being a health department I think they understood ... she understands the whole depression process and how it actually works, so I think that helped a fair bit (Participant 4).

The university staff assisted students in a variety of ways, including providing advice and opportunities for debriefing, accommodating needs and visiting students during the practice placement education experience when required. However, Baron et al (1996), Archer (1999) and Holloway (2001) identified student dissatisfaction with the university environment, policies and procedures, and staff attitudes. Participant 2, nevertheless, only accessed minimal support from the university because she felt that she would be stigmatised as a consequence of disclosing her mental illness. All participants indicated minimal contact with the university disability unit, receiving the majority of support from staff within their health disciplines. The significant role of family and friends in providing support was identified by all participants.

\section{Recommended changes}

All participants conveyed recommendations for support that could enhance successful practice placement education experiences for health professional students with a disability. There was an overwhelming suggestion from the participants to instil awareness and understanding of students with a disability in practice placement educators, university staff and other students, as well as to provide increased awareness of the support available to students with a disability themselves.

Participant 3 expressed:

... they [practice placement educators] should just be more aware that they are not going to just have to deal with people with different disabilities in work but they might have to deal with them in students as well.

Christie et al (1985) and Hummell (1997) identified a need for general practice educator education. Participant 4 suggested that enhanced education for practice placement educators was needed in regard to students with a disability, as suggested by Hirneth and Mackenzie (2004).

The participants indicated that the present nature of university support needed to be altered to allow students to feel more comfortable in approaching both university discipline staff and the disability support unit. The participants also suggested that university staff be more 'open' about issues surrounding students with a disability within lectures in order to improve the understanding of disability among peers. Other recommendations included up-to-date practice placement education information, a student mentor, opportunities to visit practice placement education sites prior to commencing the experience and a university website to allow students to liaise with other students with disabilities anonymously.

\section{Study limitations and implications for further research}

This was a small study restricted to one Australian university, with a limited response to the research invitation. Only occupational therapy and nursing students agreed to participate. Most participants perceived their experiences as successful, therefore the recruitment method may be biased in favour of students with positive experiences. This may mean that the findings cannot be generalised to all health professionals or transferable to other contexts. A larger study incorporating a range of health professional students from different universities and a longitudinal study using multiple interviews with participants throughout their practice placement education experiences would provide further information on students with a disability in the practice placement education environment.

Additional suggestions for research include looking at the differences with 'visible' and 'invisible' disabilities, a focus on students with a psychiatric disability or the comparison of different health professional student groups.

\section{Conclusion}

Since students enrolled in health professional programmes are required to undertake practice placement education, it is essential that students with a disability are supported in their preparation to become health professionals. This pilot study involved an exploration of the experiences of practice placement education for five health professional students with a disability. The findings revealed that each student had a unique experience, individual barriers were encountered and individual strategies were employed to overcome these. The participants regarded practice placement education as important and valued support as a means of achieving positive practice placement education experiences.

Although further investigation is required in this area, it is anticipated that these findings will enhance awareness of students' experiences of undertaking practice placement education with a disability and provide universities and practice placement educators with a better knowledge of the student perspective. This will allow the establishment of services to meet better the needs of health professional students with a disability during their practice placement education experiences and subsequent future careers.

\section{References}

Anderson D, Keith J, Noval P, Elliot M, eds (2002) Mosby's medical, nursing and allied health dictionary. 6 th ed. St Louis: Mosby.

Anderson M, Madill H, Warren S, Vargo J (1996) Social support and barriers to post-secondary education: experiences of students with physical disabilities in Canada. British Journal of Occupational Therapy, 59(12), 575-80. 
Archer J (1999) Essential functions: the journey of an OT student with learning disabilities. Occupational Therapy in Health Care, 11(4), 67-74.

Baron S, Phillips R, Stalker K (1996) Barriers to training for disabled social work students. Disability and Society, 11(3), 361-78.

Bruce G (2001) Defining disability. Available at: $h$ ttp://www.deakin.edu.aul tedca/ncet/education_and_training/students_with_disabilities/defining _disability.html Accessed on 9.10.04.

Christie B, Joyce P, Moeller P (1985) Fieldwork experience, part II: the supervisor's dilemma. American Journal of Occupational Therapy, 39, 675-81.

Coffey $D(2001)$ 'The experience of being an occupational therapist with a disability': What about being a student? American Journal of Occupational Therapy, 55(3), 352-53.

Commonwealth Department of Education, Science and Training (2003) Students 2003 (First half year): selected higher education statistics Appendix 4.1. Commencing and all domestic students by equity group (a), 1994-2003. Available at: $h t t p: / / w w w . d e s t . g o v . a u / h i g h e r e d /$ statistics/students/03/tables.htm Accessed on 29.08.03.

DePoy E, Gitlin L (1994) Introduction to research: multiple strategies for health and human services. St Louis: Mosby.

Elliot D, Hanzlik J, Gliner J (1992) Attitudes of occupational therapy personnel toward therapists with disabilities. Occupational Therapy Journal of Research, 12, 259-77.

Gitlow L (2001) Occupational therapy faculty attitudes toward the inclusion of students with disabilities in their educational programs. Occupational Therapy Journal of Research, 21(2), 115-31.

Grbich C (1999) Qualitative research in health: an introduction. St Leonards: Allen and Unwin.

Hammell K, Carpenter C (2000) Introduction to qualitative research in occupational therapy and physical therapy. In: K Hammell, C Carpenter, I Dyck, eds. Using qualitative research: a practical introduction for occupational and physical therapists. Edinburgh: Churchill Livingstone, 1-12, 107-19.

Hirneth M, Mackenzie L (2004) Practice education of occupational therapy students with disabilities: practice educators' perspectives. British Journal of Occupational Therapy, 67(9), 396-403.

Holloway S (2001) The experience of higher education from the perspective of disabled students. Disability and Society, 16(4), 597-615.

Hummell J (1997) Effective fieldwork supervision: occupational therapy student perspectives. Australian Occupational Therapy Journal, 44(4), 147-57.

Kornblau B (1994) Fieldwork education and students with disabilities: enter the Americans with Disabilities Act. American Journal of Occupational Therapy, 49, 139-45.

Krefting L (1991) Rigor in qualitative research: the assessment of trustworthiness. American Journal of Occupational Therapy, 45, 214-22.

Llorens L, Burton G, Still J (1999) Achieving occupational role: accommodations for students with disability. Occupational Therapy in Health Care, 11(4), 1-7.
Maheady D (1999) Jumping through hoops, walking on egg shells: the experiences of nursing students with disabilities. Journal of Nursing Education, 38(4), 162-70.

Marks B (2000) Jumping through hoops, walking on egg shells or discrimination, hazing and abuse of students with disabilities? Journal of Nursing Education, 39(5), 205-10.

Mitchell M, Kampfe C (1990) Coping strategies used by occupational therapy students during fieldwork: an exploratory study. American Journal of Occupational Therapy, 44, 543-50.

New South Wales Ageing and Disability Department (1998) NSW Government Disability Policy Framework. Sydney: NSWADD.

Patton M (2002) Qualitative research and evaluation methods. 3rd ed. Thousand Oaks, CA: Sage.

Paul S (1999) Students with disabilities in post-secondary education: the perspectives of wheelchair users. Occupational Therapy International, 6(2), 90-109.

Pohl C, Winland-Brown J (1992) The meaning of disability in a caring environment. Journal of Nursing Administration, 22, 29-35.

Rangel A, Wittry A, Boucher B, Sanders B (2001) A survey of essential functions and reasonable accommodations in physical therapist education programs. Journal of Physical Therapy Education, 15, 11-19.

Skill: National Bureau for Students with Disabilities (2005) Available at: http://www.skill.org.uk/info/case_studies/ruth_douglas.asp Accessed on 03.02.05.

Suto M (2000) Issues related to data collection. In: K Hammell, C Carpenter, I Dyck, eds. Using qualitative research: a practical introduction for occupational and physical therapists. Edinburgh: Churchill Livingstone, 25-46.

Tompson M, Ryan A (1996) Students' perspectives of fieldwork: process, purpose and relationship to coursework. Australian Occupational Therapy Journal, 43(3-4), 95-104.

Velde B (2000) The experience of being an occupational therapist with a disability. American Journal of Occupational Therapy, 54(2), 183-88.

Weiner $E$ (1999) The meaning of education for university students with a psychiatric disability: a grounded theory analysis. Psychiatric Rehabilitation Journal, 22(4), 403-409.

Wright D (2000) Educational support for nursing and midwifery students with dyslexia. Nursing Standard, 14(41), 35-41.

\section{Authors}

Kate Brown, BOccTher, Occupational Therapist, Maitland Hospital, Maitland, NSW, Australia.

Carole James, MHSc(OT), BSc(OT), DipCOT, Lecturer, School of Health Sciences, Hunter Building, University of Newcastle, University Drive, Callaghan, NSW 2308, Australia. Email: Carole.James@newcastle.edu.au Lynette Mackenzie, PhD, MEd, BSc(OT), DipCOT, Senior Lecturer, Discipline of Occupational Therapy, School of Health Sciences, Hunter Building, University of Newcastle, University Drive, Callaghan, NSW 2308, Australia. Email: Lynette.Mackenzie@newcastle.edu.au 